\title{
Hyperpigmentation: Its Historical Treatment and the Development of Hydroquinone
}

James J Nordlund*

Department of Dermatology, Wright State Boonshoft School of Medicine, Dayton, Ohio, USA

${ }^{*}$ Corresponding author: Department of Dermatology, Wright State Boonshoft School of Medicine, Dayton, Ohio, USA, Tel: + 0115138714168; E-mail: jjnordlund@fuse.net

Rec date: October 10, 2015; Acc date: October 13, 2015; Pub date: October 20, 2015

Copyright: ( 2015 Nordlund JJ. This is an open-access article distributed under the terms of the Creative Commons Attribution License, which permits unrestricted use, distribution, and reproduction in any medium, provided the original author and source are credited.

\section{Abstract}

Skin color has always been important and interest to people in all cultures. Disorders of skin color, either hyperor hypopigmentation are cosmetically vexing and can be signs of systemic disease. For many centuries physicians have tried to treat such disorders. We review some of the history of treatments for hyperpigmentation and the development of hydroquinone, currently the medication of choice for hyperpigmentation.

Keywords: Pigmentation; Hyperpigmentation; Treatments; Hydroquinone

\section{Introduction}

Skin color has been a distinguishing feature of humans and of interest to the earliest humans writing about health. Already in the Old Testament the writers suggested that Noah, builder of the ark, was an albino [1]. In the Egyptian Ebers Papyrus (1500 BCE) there are descriptions of individuals with white spots on the skin, i.e., a recognition of skin color and its disorders [2]. Similar descriptions have been found in Indian Atharva Veda (1400 BCE) and Japanese literature Makatominoharai (1200 BCE). Herodotus, a Greek author, writing about $450 \mathrm{BCE}$ discusses white spots [3]. Clearly people from ancient times were fascinated by skin colour and its disorders.

It was much later that scientists began to study skin color and its origin [4] Some medieval workers, noting that most darker skinned individuals lived in or came from Africa, thought dark skin was caused by the sun and heat of the tropics. Others noted that Africans emigrating to cooler and less sunny climates in Europe did not lose their color and their children retained the dark skin of their parents. They suggested that hepatic humors deposited beneath the skin thereby giving the skin its color. To prove this, they had black volunteers produce burn blisters. After removing the blister and observing the dermal side, early scientists noted that the pigment was indeed on the lowest layer of the epidermis. The observations confirmed their hypothesis about color coming from deposition of hepatic humors [4].

It was not until the invention of the microscope that cells were observed and the structure of the skin and distribution of pigmentation was properly worked out, a process that continued well into the 20th century [4].

As noted there was great interest in discoloration of the skin, disorders as vitiligo and chloasma [5]. Dr. Jocobi suggests there was no treatment for vitiligo. Chloasma was considered an hypertrophy of the pigmentation often associated with pregnancy. Because it often resolved after the pregnancy was completed no therapy was required. The available remedies recommended for hyperpigmentation were applications of $1 \%$ solution of corrosive sublimate in spirits or rubbing with resorcin paste till scaling was produced. Unfortunately none of these therapies produced permanent removal of the hyperpigmentation [5].

\section{Hyperpigmentation and its treatment: early attempts}

The earliest therapies suggested by Jacobi [5] were unsuccessful. A variety of other agents were utilized to lighten disfiguring hyperpigmentation. These included applications of borax, sulfur, tincture of iodine, potassium and sodium hydroxide. These were prepared in complex formulations some of which were poisonous and many produced rapid desquamation of the epidermis. Blisters were a complication. It was noted that hyperemia following these treatments caused post inflammatory hyperpigmentation [6]. Ormsby stated "Those methods which effectively and brilliantly accomplish the desired end temporarily are almost invariably followed by deeper pigmentation that that which was attempted to remove" [6]. Ammoniated mercury 3\% in a cream had been used to lighten skin [7-11]. It apparently was partially successful at least as an exfoliating agent [10] but the mercury is known to be toxic and the product was a frequent cause of contact dermatitis. Hypochlorite bleach, salicylic acid and ascorbic acid both topical and systemic, were used with minimal or no efficacy $[7,10]$. In contrast sunscreens such as red veterinary petrolatum and steroids, both topical and oral especially for those with Addison's disease, were useful at least as adjunctive therapies [10]. The efforts and clinical trials substantiate the idea that disorders of skin color such as hyperpigmentation were a significant problem.

\section{Occupational leukoderma and monobenzyl ether of hydroquinone}

In the 1930's, Edward Oliver and his coworkers studied a group of workers in a leather tanning factory who had experienced total loss of pigmentation from their hands and forearms [12]. A few workers noted depigmentation also at distant sites of the body such as the trunk. The depigmented skin corresponded to skin covered by a rubber gauntlet gloves worn for protection during the tanning process. The palms and finger tips were spared. Some of the workers experienced 
itching while wearing the gloves although most did not develop a rash. Hair color on the arms and hands was not affected.

The investigators noted that 48 individuals in the factory wore the rubber gloves and 25 (52\%) had leukoderma. The percentage of those with leukoderma seemed to vary with the duration of time the workers wore the gloves during their work shifts. The investigators learned that the manufacturer of the rubber gloves had changed its method of production and added the antioxidant agerite alba, an ingredient that improved the stability and aging properties of the rubber. Agerite alba chemically is monobenzyl ether of hydroquinone (monobenzone). Patch testing of 10 men with depigmentation by application of various chemicals including monobenzone (agerite alba) produced color loss at the site of the patch tests. Additional studies confirmed that agerite alba (monobenzone) was indeed the culprit. Many of the affected workers noted repigmentation of their hands and arms after discontinuing the use of the rubber gloves. There were no deleterious health effects noted in the affected workers.

A decade later, investigators interested in finding treatments for hyperpigmentation undertook a series of studies on three chemicals, i.e., monobenzone, hydroquinone and para-hydroxypropiophenone [7]. These three chemicals were chosen based on earlier publications reporting their hypopigmenting effects on skin and hair color. Prior investigators observed that hydroquinone mixed into food of cats lightened the color of their fur [13]. Oliver [12] had reported the depigmenting effects of monobenzone. French workers noted the beneficial effects of para-hydroxypropiophenone on the hyperpigmentation of five patients with Riehl's melanosis. Both in vivo and in vitro experiments were undertaken on these three chemicals [7].

In vitro, it was observed that hydroquinone completely inhibited tyrosinase function and melanin formation whereas propiophenone has no effect. Monobenzone stimulated melanin formation. When fed to black guinea pigs, minimal pigment loss was noted in animals receiving hydroquinone ( 1 of 5 guinea pigs) and monobenzone ( 3 of 5 pigs).

Clinical studies on normal humans were conducted by the same investigators [7]. Young males had patch tests containing $10 \%$ or $30 \%$ hydroquinone, monobenzone and hydroxypropiophenone applied to their backs for a period of 30 days. The higher doses of hydroquinone and monobenzone produced some color loss in two subjects by the end of the study. The skin repigmented within a month.

In a separate study $20 \%$ monobenzone was applied to the skin of 70 normal individuals as a patch test for 48 hours. No contact sensitivity was observed. In a final study, 7 patients with various disorders of hyperpigmentation were treated with $20 \%$ or higher concentrations of monobenzyl ether of hydroquinone. At least 5 showed some improvement with no deleterious effects. The authors concluded "... hydroquinone derivatives, such as monobenzyl ether of hydroquinone..., are effective clinical agents for treating hyperpigmentation due to melanin. When properly employed in 10 to 33 per cent concentration in lotions or ointments, monobenzyl ether of hydroquinone is a valuable local therapeutic agent. Undesirable side reaction such as dermatitis does not preclude its controlled medical use" [7].

The same investigators completed another clinical study a year later. Eighty-four patients with melanin hyperpigmentation were recruited for the study. They suffered from various pigmentary problems such as melasma, berlock dermatitis, nevi, lentigines, café au lait spots, seborrheic keratosis and freckles. The patients applied a $20 \%$ ointment of monobenzyl ether of hydroquinone [14]. Sixty-four patients showed a good clinical response after two to six months treatment. Treatment was considered highly successful for some of the conditions particularly for melasma and post inflammatory hyperpigmentation. Other observers reported similar beneficial results with applications of monobenzone to treat hyperpigmentation [15].

Within a few years reports appeared in the literature describing the permanent and disfiguring leukomelanoderma caused by applications of monobenzyl ether of hydroquinone when used for disorders of hyperpigmentation [16-21]. It was removed from the dermatological formulary after these reports. The beneficial efficacy in depigmenting patients with vitiligo too extensive to repigment has been noted [22]. Currently monobenzone is used exclusively for this purpose. Other chemicals such as 4-isopropylcatechol with structures similar to monobenzone have been found to be effective for lightening skin [23] but are not commercially available.

\section{The advent of hydroquinone as a skin lightener}

Lightening hyperpigmented skin caused by melanin has always been problematic [24]. The various desquamating agents, ascorbic acid, sunscreens were not helpful. Hydroquinone commercially available as Eldoquin was at least partially successful.

That hydroquinone might be effective has a basis in scientific data. Denton, Lerner and Fitzpatrick had demonstrated that hydroquinone in vitro entirely blocked the formation of melanin when added to a solution containing tyrosinase and tyrosine, the enzyme and substrate required for melanin production. Hydroquinone had no effect on melanin formation by tyrosinase in the presence of dopa [7]. The same investigators did clinical studies on hydroquinone (see above) and found it less effective than monobenzone in reducing normal or abnormal skin color.

In 1961, Dr. Malcolm Spencer published his study on 98 white and African American males treated with various concentrations of hydroquinone and two derivatives of this molecule. The subjects applied various concentrations of the medications up to $10 \%$ for a period of four months. Some subjects applying 5\% hydroquinone noted irritation of the skin that resolved when a $2 \%$ preparation of hydroquinone was substituted. Skin lightened in $45 \%$ of the subjects and there was more pronounced improvement noted in white subjects than those with darker complexions $[8,25]$. Very high concentrations of hydroquinone, $10 \%$ to $30 \%$ were noted to deposit a dark substance on the skin produced by auto-oxidation of the molecule [8]. These reports are the first documentation of the efficacy and safety of hydroquinone for clinical use. It was this study that introduced hydroquinone for clinical use [9].

A few years later several studies confirmed that a stabilized form of hydroquinone was a useful medication to lighten skin color. Spencer studied the effects of $2 \%, 3 \%$ and $5 \%$ hydroquinone on "old age spots" on the hands of 94 white males and 43 African American men with normal skin. About $2 / 3$ of these individuals exhibited some but not total pigment suppression. The results were more pronounced with the $3 \%$ and $5 \%$ preparation. Irritation was commonly noted and 2 individuals developed an allergic contact dermatitis confirmed by patch testing. Histological studies using $\mathrm{H} \& \mathrm{E}$ and silver nitrate stains confirmed that the quantity of melanin in the treated skin was diminished but the number of melanocytes remained constant [10]. 
The authors concluded that at that time hydroquinone was at least an acceptable agent for lightening skin.

At the same time, another group published the results of their studies on $2 \%$ and $5 \%$ hydroquinone on hyperpigmented skin of 56 patients. They observed it was moderately effective in $80 \%$ of the treated subjects and that the two concentrations were equally effective. They concluded that hydroquinone did not completely resolve pathological hyperpigmentation but results were sufficiently satisfactory to help most patients [9].

Albert Kligman developed a new formula for lightening skin. He combined $0.1 \%$ tretinoin, $5 \%$ hydroquinone and $0.1 \%$ dexamethasone into an ointment. It was very effective and able to suppress completely melanin formation in normal black skin [26]. Omission of any one of the ingredients abolished the hypopigmenting efficacy. Histological studies showed that the number of melanocytes $/ \mathrm{mm}^{2}$ (population density) actually increased after the application of this preparation.

Many studies on the efficacy of hydroquinone with and without other therapeutic modalities have been published. [27-32]. It has become the drug of choice for skin hyperpigmentation and is prescribed around the world. A combination, commercial product, TriLuma containing a retinoid (tretinoin 0.05\%), a steroid (fluocinolone acetonide $0.01 \%$ ) and hydroquinone (4\%), (a version of the Kligman formula) has become available and found to be effective for up to $90 \%$ patients with epidermal melanin hyperpigmentation [33].

\section{Some concerns about the use of hydroquinone}

In the last few years there has been concern about the safety of hydroquinone and it's over the counter use has been banned in Europe and the American FDA has requested new safety studies. It is well documented that hydroquinone, especially in higher concentrations such as $5 \%$ can be an irritant and allergen. Its chronic use can induce ochronosis rarely [34-42], nail discoloration and conjunctival melanosis. Rarely the melanosis causes corneal damage and some loss of visual acuity [43]. It has also been of concern that hydroquinone might cause permanent depigmentation similar to monobenzone. It has been shown that hydroquinone produces damage to melanocytes detectable by various forms of microscopy [44]. However a review of the world's literature failed to substantiate that hydroquinone clinical has caused permanent leukoderma [45]. It many of the reported cases of leukoderma, patients had been applying monobenzyl ether of hydroquinone and not hydroquinone.

Concerns have been raised about whether hydroquinone is a carcinogen [46]. It has been shown that hydroquinone injected into certain strains of rats can induce renal adenomas and toxicity in mice $[43,47,48]$. Benzene is a known carcinogen causing aplastic anemia or myelogenous leukemia in humans [43,49-51]. Benzene is converted into hydroquinone in the liver and excreted into the urine. It has been suggested that it is the hydroquinone and not the benzene that is responsible for the bone marrow toxicity in humans. Thus there is the concern of regulatory agencies.

Hydroquinone is an ubiquitous chemical found in many foods and herbal medications. Common foods such as red wine, coffee, tea, wheat and fruits contain small to large amounts of hydroquinone. Hydroquinone is found in small amounts in the blood and urine of most individuals. It has been estimated that individuals excrete 2770 $\mu \mathrm{gms}$ of hydroquinone daily [52]. Volunteers have consumed orally up to $500 \mathrm{gm}$ daily for five months with no detectable ill effects $[43,53]$. In comparison the quantity of hydroquinone absorbed into the blood stream by applications of hydroquinone to small areas of skin is insignificant. In confirmation, Pifer et al. has studied large populations of individuals engaged in the manufacture of hydroquinone who are exposed to vapors of hydroquinone for prolonged periods of time. Pifer compared rates of cancer, early death and systemic illness afflicting the workers to those affecting the population at large. They observed that the workers exposed to hydroquinone vapors had better health profiles on all measured parameters than the control population $[54,55]$.

\section{The future}

Hydroquinone alone or in combination is the best available lightening agent available to treat those with disfiguring melanin discoloration of the skin. It is only partially effective. It has no effect on pre-existing melanin such as is found in dermal melanosis but rather only formation of new melanin such as occurs in epidermal melanosis. [56]. Although its efficacy is much improved when combined with other agents such as the Kligman formula (see above), better agents are needed. Other chemicals such as kojic acid have been introduced to dermatology [57-59] but are no more effective than hydroquinone. Scientists, clinicians, pharmaceutical and cosmetic companies are seeking newer and better lightening agents. One such chemical might be deoxyarbutin, a derivative of hydroquinone with a carbohydrate moiety attached. It seems to be significantly more effective in inhibiting melanin formation than hydroquinone [60-67]. It would be a real benefit to people at large, especially those with darker skins who are affected most commonly by hyperpigmentation, if a better, inexpensive and safe lightening agent were identified and made available commercially.

\section{References}

1. Schneir L (2003) Albinism and Genetics in the Bible. 31: 1-4.

2. Kopera D (2000) History and Cultural Aspects of Vitiligo. Oxford, Blackwell Science, USA.

3. Ortonne J, Mosher DB, Fiztpatrick TB (1983) Disorders with circumscribed hypomelanoses. Vitiligo and Other Hypomelanoses of Hair and Skin, Plenum Publishing, New York, USA.

4. Klaus SN (2006) A History of the Science of Skin Pigmentation. The Pigmentary System, Oxford, Blackwell Publishing, USA.

5. Jacobi P (1904) Portfolio of Dermochromes. (2ndedn), Rebman Company, New York, USA.

6. Ormsby O (1927) A Practical Treatise on Diseases of the Skin. (3rdedn), Lea and Febiger, Philadelphia, USA.

7. Denton CR, Lerner AB, Fitzpatrick TB (1952) Inhibition of melanin formation by chemical agents. J Invest Dermatol 18: 119-135.

8. Spencer MC, Becker SW Jr (1963) A hydroquinone effect. Clin Med (Northfield) 70: 1111-1114.

9. Arndt KA, Fitzpatrick TB (1965) Topical use of hydroquinone as a depigmenting agent. JAMA 194: 965-967.

10. Spencer MC (1965) Topical use of hydroquinone for depigmentation. JAMA 194: 962-964.

11. Barber ED, Hill T, Schum DB (1995) The percutaneous absorption of hydroquinone (HQ) through rat and human skin in vitro. Toxicol Lett 80 : 167-172.

12. Oliver E, Schwartz L, Warren L (1940) Occupational Leukoderma. Arch Dermatol and Syphilology 42: 993-1007.

13. Martin GJ (1941) Confirmatory evidence of the chromotrichial activity of p-aminobenzoic acid. J. Biol. Chem 138: 441-444. 
14. Lerner AB, Fitzpatrick TB (1953) Treatment of melanin hyperpigmentation. J Am Med Assoc 152: 577-582.

15. Pollock JH (1950) Hyperpigmentation improved by treatment with monobenzyl ether of hydroquinone. Arch Derm Syphilol 61: 873-875.

16. Chivers CP (1972) Two cases of occupational leucoderma following contact with hydroquinone monomethyl ether. Br J Ind Med 29: 105-107.

17. Markey AC, Black AK, Rycroft RJ (1989) Confetti-like depigmentation from hydroquinone. Contact Dermatitis 20: 148-149.

18. O'Sullivan JJ, Stevenson CJ (1981) Screening for occupational vitiligo in workers exposed to hydroquinone monomethyl ether and to paratertiaryamyl-phenol. Br J Ind Med 38: 381-383.

19. Bentley-Phillips B, Bayles MA (1975) Cutaneous reactions to topical application of hydroquinone. Results of a 6-year investigation. S Afr Med J 49: 1391-1395.

20. Dorsey CS (1960) Dermatitic and pigmentary reactions to monobenzyl ether of hydroquinone: report of two cases. Arch Dermatol 81: 245-248.

21. Canizares O, Uribe Jaramillo F, Kerdel Vegas F (1958) Leukomelanoderma subsequent to the application of monobenzyl ether of hydroquinone; a vitiligoid reaction observed in Colombia and Venezuela. AMA Arch Derm 77: 220-223.

22. Mosher DB, Parrish JA, Fitzpatrick TB (1977) Monobenzylether of hydroquinone. A retrospective study of treatment of 18 vitiligo patients and a review of the literature. Br J Dermatol 97: 669-679.

23. Bleehen SS (1976) The treatment of hypermelanosis with 4isopropylcatechol. Br J Dermatol 94: 687-694.

24. Becker SW Jr (1965) Therapy of Melanin Hyperpigmentation. Postgrad Med 37: 198-201.

25. Spencer MC (1961) Hydroquinone Bleaching. Arch Dermatol 84: 131-134.

26. Kligman AM, Willis I (1975) A new formula for depigmenting human skin. Arch Dermatol 111: 40-48.

27. Kakita LS, Lowe NJ (1998) Azelaic acid and glycolic acid combination therapy for facial hyperpigmentation in darker-skinned patients: a clinical comparison with hydroquinone. Clin Ther 20: 960-970.

28. Haddad AL, Matos LF, Brunstein F, Ferreira LM, Silva A, et al. (2003) A clinical, prospective, randomized, double-blind trial comparing skin whitening complex with hydroquinone vs. placebo in the treatment of melasma. Int J Dermatol 42: 153-156.

29. Astaneh R, Farboud E, Nazemi MJ (2005) 4\% hydroquinone versus $4 \%$ hydroquinone, $0.05 \%$ dexamethasone and $0.05 \%$ tretinoin in the treatment of melasma: a comparative study. Int J Dermatol 44: 599-601.

30. Guevara IL, Pandya AG (2003) Safety and efficacy of $4 \%$ hydroquinone combined with $10 \%$ glycolic acid, antioxidants, and sunscreen in the treatment of melasma. Int J Dermatol 42: 966-972.

31. Taylor SC, Torok H, Jones T, Lowe N, Rich P, et al. (2003) Efficacy and safety of a new triple-combination agent for the treatment of facial melasma. Cutis 72: 67-72.

32. Grimes PE (2004) A microsponge formulation of hydroquinone $4 \%$ and retinol $0.15 \%$ in the treatment of melasma and postinflammatory hyperpigmentation. Cutis 74: 362-368.

33. Torok HM, Jones T, Rich P, Smith S, Tschen E (2005) Hydroquinone 4\%, tretinoin $0.05 \%$, fluocinolone acetonide $0.01 \%$ : a safe and efficacious 12 month treatment for melasma. Cutis 75: 57-62.

34. Hardwick N, Van Gelder LW, Van der Merwe CA, Van der Merwe MP (1989) Exogenous ochronosis: an epidemiological study. Br J Dermatol 120: 229-238.

35. Hull PR, Procter PR (1990) The melanocyte: an essential link in hydroquinone-induced ochronosis. J Am Acad Dermatol 22: 529-531

36. Lawrence N, Bligard CA, Reed R, Perret WJ (1988) Exogenous ochronosis in the United States. J Am Acad Dermatol 18: 1207-1211.

37. Findlay GH, Morrison JG, Simson IW (1975) Exogenous ochronosis and pigmented colloid milium from hydroquinone bleaching creams. Br J Dermatol 93: 613-622.

38. Findlay GH (1982) Ochronosis following skin bleaching with hydroquinone. J Am Acad Dermatol 6: 1092-1093.
39. Hoshaw RA, Zimmerman KG, Menter A (1985) Ochronosislike pigmentation from hydroquinone bleaching creams in American blacks. Arch Dermatol 121: 105-108.

40. Phillips JI, Isaacson C, Carman H (1986) Ochronosis in black South Africans who used skin lighteners. Am J Dermatopathol 8: 14-21.

41. Tidman MJ, Horton JJ, MacDonald DM (1986) Hydroquinone-induced ochronosis--light and electronmicroscopic features. Clin Exp Dermatol 11: 224-228.

42. Weiss RM, del Fabbro E, Kolisang P (1990) Cosmetic ochronosis caused by bleaching creams containing 2\% hydroquinone. S Afr Med J 77: 373.

43. DeCaprio AP (1999) The toxicology of hydroquinone--relevance to occupational and environmental exposure. Crit Rev Toxicol 29: 283-330.

44. Jimbow K, Obata H, Pathak MA, Fitzpatrick TB (1974) Mechanism of depigmentation by hydroquinone. J Invest Dermatol 62: 436-449.

45. Cummings M, Nordlund JJ (1995) Chemical Leukoderma: Fact or Fancy. Amer J Contact Derm 6: 122-127.

46. Westerhof W, Kooyers TJ (2005) Hydroquinone and its analogues in dermatology - a potential health risk. J Cosmet Dermatol 4: 55-59.

47. Hard GC, Whysner J, English JC, Zang E, Williams GM (1997) Relationship of hydroquinone-associated rat renal tumors with spontaneous chronic progressive nephropathy. Toxicologic Pathology 25: $132-143$.

48. Kari FW, Bucher J, Eustis SL, Haseman JK, Huff JE (1992) Toxicity and carcinogenicity of hydroquinone in $\mathrm{F} 344 / \mathrm{N}$ rats and $\mathrm{B} 6 \mathrm{C} 3 \mathrm{~F} 1$ mice. Food Chem Toxicol 30: 737-747.

49. Kalf GF (1987) Recent advances in the metabolism and toxicity of benzene. Crit Rev Toxicol 18: 141-159.

50. Rinsky RA, Smith AB, Hornung R, Filloon TG, Young RJ, et al. (1987) Benzene and leukemia. An epidemiologic risk assessment. N Engl J Med 316: 1044-1050.

51. Smith MT (1996) Overview of benzene-induced aplastic anaemia. Eur J Haematol Suppl 60: 107-110.

52. Nordlund JJ, Grimes PE, Ortonne JP (2006) The safety of hydroquinone. J Eur Acad Dermatol Venereol 20: 781-787.

53. Carlson AJ, Brewer NR (1953) Toxicity studies on hydroquinone. Proc Soc Exp Biol Med 84: 684-688.

54. Pifer JW, Hearne FT, Friedlander BR, McDonough JR (1986) Mortality study of men employed at a large chemical plant, 1972 through 1982. J Occup Med 28: 438-444.

55. Pifer JW, Hearne FT, Swanson FA, O'Donoghue JL (1995) Mortality study of employees engaged in the manufacture and use of hydroquinone. International Archives of Occupational \& Environmental Health 67: 267-280.

56. Nordlund JJ, Boissy RE, Hearing VJ, King RA, Oetting, W, et al. (2006) The Pigmentary System: Physiology and Pathophysiology. (2ndedn), Oxford, Blackwell Scientific Publishers, USA.

57. Cabanes J, Chazarra S, Garcia-Carmona F (1994) Kojic acid, a cosmetic skin whitening agent, is a slow-binding inhibitor of catecholase activity of tyrosinase. J Pharm Pharmacol 46: 982-985.

58. Lim JT (1999) Treatment of melasma using kojic acid in a gel containing hydroquinone and glycolic acid. Dermatol Surg 25: 282-284.

59. Garcia A, Fulton JE Jr (1996) The combination of glycolic acid and hydroquinone or kojic acid for the treatment of melasma and related conditions. Dermatol Surg 22: 443-447.

60. Boissy RE, Visscher M, DeLong MA (2005) DeoxyArbutin: a novel reversible tyrosinase inhibitor with effective in vivo skin lightening potency. Exp Dermatol 14: 601-608.

61. Daniel BS, Wittal R (2015) Vitiligo treatment update. Australas J Dermatol 56: 85-92.

62. Laddha NC, Dwivedi M, Mansuri MS, Gani AR, Ansarullah M, et al (2013) Vitiligo: interplay between oxidative stress and immune system. Exp Dermatol 22: 245-250.

63. Nunes DH, Esser LM (2011) Vitiligo epidemiological profile and the association with thyroid disease. An Bras Dermatol 86: 241-248. 
Citation: Nordlund JJ (2015) Hyperpigmentation: Its Historical Treatment and the Development of Hydroquinone. Pigmentary Disorders 2: 221. doi:10.4172/2376-0427.1000221

Page 5 of 5

64. Nejad SB, Qadim HH, Nazeman L, Fadaii R, Goldust M (2013) Frequency of autoimmune diseases in those suffering from vitiligo in comparison with normal population. Pak J Biol Sci 16: 570-574.

65. Gopal KV, Rao GR, Kumar YH (2014) Increased prevalence of thyroid dysfunction and diabetes mellitus in Indian vitiligo patients: A casecontrol study. Indian Dermatol Online J 5: 456-460.
66. Sehgal VN (2011) Vitiligo and alopecia areata associated with subclinical/ clinical hypothyroidism. Skinmed 9: 192-194.

67. Colucci R, Lotti F, Dragoni F, Arunachalam M, Lotti T, et al. (2014) High prevalence of circulating autoantibodies against thyroid hormones in vitiligo and correlation with clinical and historical parameters of patients. Br J Dermatol 171: 786-798. 